\title{
Plant size and reproductive state affect the quantity and quality of rewards to animal mutualists
}

\author{
Tom E. X. Miller* \\ Department of Ecology and Evolutionary Biology, Rice University, Houston, TX 77005, USA
}

\begin{abstract}
Summary
1. Many plants engage ants in defensive mutualisms by offering extrafloral nectar (EFN). Identifying sources of variation in EFN quantity (amount) and quality (composition) is important because they can affect ant visitation and identity and hence effectiveness of plant defence.

2. I investigated plant size and reproductive state (vegetative or flowering) as sources of variation in EFN quantity and quality. I focused on Opuntia imbricata and two ant partners, Crematogaster opuntiae and Liometopum apiculatum. I tested the influence of plant size and nectary type (vegetative vs. reproductive structure) on the probability and rate of EFN secretion, concentrations of total carbohydrates $(\mathrm{CH})$ and amino acids (AAs), and relative abundances of constituent $\mathrm{CH}$ and AAs. I also examined how traits of individual nectaries scaled up to influence total plant-level rewards. Parallel observations documented associations between plant demographic state and ant visitation and species identity.

3. EFN quantity and quality were generally greater for larger, reproductive plants. At the scale of individual nectaries, probability of EFN secretion was positively size-dependent and greater for nectaries on reproductive vs. vegetative structures. Rate of EFN secretion, carbohydrate and amino acid concentrations, and the relative abundance of disaccharide vs. monosaccharide sugars were greater for reproductive nectaries but were unaffected by plant size.

4. Nectary-level traits scaled up to influence rewards at the whole-plant level in ways that corresponded to ant visitation: the probability of ant occupancy increased with plant size and reproduction, as did the likelihood of being tended by the superior guard, L. apiculatum. Variability in EFN traits may contribute to changes in ant occupancy and identity across plant sizes and reproductive states.

5. Synthesis. This study provides a thorough examination of how plant investment in biotic defence varies over the life cycle. Explicit consideration of plant demography may enhance understanding of ant-plant mutualisms. Populations of long-lived plants are demographically heterogeneous, spanning sizes and reproductive states. The rewards offered to animal mutualists can track demographic heterogeneity with consequences for plant defence and the dynamics of multispecies mutualisms.
\end{abstract}

Key-words: ant-plant mutualism, biotic defence, demography, extrafloral nectar, invertase, ontogeny, plant development and life-history traits, stage structure

\section{Introduction}

Plants face varying pressures from herbivores as they progress through their life cycle. A large body of work has examined the ontogeny of plant defence and the ways in which it is shaped by stage- or size-specific selection by herbivores (reviewed in Boege \& Marquis 2005; Barton \& Koricheva 2010). Examining ontogenetic variation in defence can inform understanding of how plants resolve optimality problems associated with allocation to growth and defence over the life

*Correspondence author. E-mail: tom.miller@rice.edu cycle. Much of this work has focused on physical or chemical defences (e.g. Ohnmeiss \& Baldwin 2000). In addition, ontogenetic variation in indirect (biotic) defences, particularly traits that mediate defensive mutualisms with ants, has received increasing attention (Heil et al. 2000; Trager \& Bruna 2006; Pringle, Dirzo \& Gordon 2012; Villamil, Marquez-Guzman \& Boege 2013). Just as ontogenetic variation in direct defence is important for understanding plantherbivore interactions (Barton \& Koricheva 2010), variation in indirect defence traits may be important for understanding the dynamics of plant-animal mutualisms.

Extrafloral nectar (EFN) is a common currency with which ant protection is traded. This indirect defence strategy is 
employed widely across plant families (Koptur 1992; Marazzi, Bronstein \& Koptur 2013). EFN is a complex reward that can vary in many dimensions, including rate of secretion, concentrations of total carbohydrates $(\mathrm{CHs})$ and free amino acids (AAs), relative abundances of constituent $\mathrm{CHs}$ and AAs, and even secondary compounds and active enzymes (Heil 2011). Identifying sources of variation in these EFN traits is important because they can influence the quantity and quality of ant defence. For example, ant patrolling tends to increase with rate of EFN secretion (Kost \& Heil 2005; Villamil, Marquez-Guzman \& Boege 2013), and partner identity and their aggression towards herbivores can vary with $\mathrm{CH}$ and AA composition (Blüthgen \& Fiedler 2004; GonzalezTeuber \& Heil 2009; Ness, Morris \& Bronstein 2009; Wilder \& Eubanks 2010; Shenoy et al. 2012). The relative abundance of monosaccharide vs. disaccharide sugars has emerged as a particularly important dimension of EFN variability because ant species can differ in their abilities to digest disaccharides (Heil, Rattke \& Boland 2005; Kautz et al. 2009). Any EFN traits that influence ant species identity could have consequences for defence because ant species are often unequal in their abilities to protect plants from herbivores (e.g. Ness, Morris \& Bronstein 2006).

While EFN traits can clearly have important ecological consequences, we are just beginning to understand how these traits vary with plant demographic state (size or life stage) and translate to variation in realized defence. Studies across a variety of systems have shown that EFN production (or ant activity, often used as a proxy for EFN production) increases with plant size or age and is greater on reproductive plants or plant parts than on vegetative plants or plant parts (Wäckers \& Bonifay 2004; Trager \& Bruna 2006; Miller 2007; Shenoy et al. 2012; Villamil, Marquez-Guzman \& Boege 2013). Recent studies also suggest that $\mathrm{CH}$ and AA concentration and composition can change with reproductive state, with generally sweeter nectar on reproductive vs. vegetative plants or plant parts (Shenoy et al. 2012; Villamil, MarquezGuzman \& Boege 2013). Associations between EFN quantity/ quality and plant size and reproductive state have been interpreted in the light of optimal defence theory (e.g. Wäckers \& Bonifay 2004; Holland, Chamberlain \& Horn 2009), which predicts that plants should maximize defence of structures that contribute most to fitness (Rhoades 1979).

Shifts in EFN traits associated with plant reproduction may be manifested at multiple scales. At a smaller scale, there may be differences in the amount or type of EFN secreted by individual EFNs on reproductive structures vs. nectaries on vegetative plant parts (e.g. Wäckers \& Bonifay 2004; Shenoy et al. 2012). At a larger scale, the onset of reproduction may lead to different amounts or types of EFN secreted from vegetative vs. reproductive plants (Villamil, Marquez-Guzman \& Boege 2013). Finally, the ways in which nectary-level traits scale up to influence rewards at the whole-plant level depend on how the total number of nectaries and relative allocation between vegetative and reproductive structures scale with plant development. No previous studies have integrated the influence of plant size and reproductive status over multiple scales. Furthermore, because reproductive status is often positively correlated with plant size, the relative contributions of these variables to ontogenetic variation remain unclear.

Unlike direct defences, EFN is both a plant defence trait and a resource that mediates multispecies interactions (Rudgers \& Gardener 2004; Holland, Chamberlain \& Miller 2011) and is therefore important to consider from the ants' perspectives as well as the plants' (Lanan \& Bronstein 2013). Plant size- or stage-related variation in EFN production and composition may have consequences for the guild of ant partner species that rely on this reward. For example, ontogenetic shifts in ant partner identity have emerged as an intriguing pattern across ant-plant defensive mutualisms, with different ant species associating non-randomly with different plant life stages (Young, Stubblefield \& Isbell 1997; Fonseca \& Benson 2003; Djieto-Lordon et al. 2004; Miller 2007; Palmer et al. 2010; Miller \& Rudolf 2011). Little is known about mechanisms underlying these patterns. Whether variation in plant rewards underlies shifts in partner association remains an open question. At the population level, plant size- or stage-related variation in EFN could generate resource heterogeneity, potentially expanding opportunities for coexistence of multiple ant partners (Young, Stubblefield \& Isbell 1997; Lee \& Inouye 2010). Genotype differences could also contribute to population-level variation in rewards (e.g. Ballhorn, Godschalx \& Kautz 2013).

In this study, I quantified variation in EFN quantity and quality in a long-lived desert plant, the tree cholla cactus, Opuntia imbricata Haw. [D.C.]. While 'ontogenetic variation' is widely used in the plant defence literature, here I focus on plant size and reproductive state (vegetative or flowering), two important axes of ontogeny. I examined multiple dimensions of EFN variability, including presence/absence of EFN, rate of secretion, concentrations of total $\mathrm{CHs}$ and $\mathrm{AAs}$, and relative abundances of component $\mathrm{CHs}$ and AAs across plant sizes and stages. I employed a sampling design and statistical approach that allowed me to quantify the independent and interactive effects of plant size and reproductive state and test for their effects at small (nectary-level) and large (plant-level) scales. To connect nectar traits to ant-plant interactions, I also documented associations between plant demographic state and interactions with ants, including visitation and species identity.

\section{Materials and methods}

\section{STUDY SYSTEM}

This study was conducted in the Los Piños mountains, a small mountain chain located on the Sevilleta National Wildlife Refuge, a Longterm Ecological Research (LTER) site in central New Mexico, USA. The Los Piños mountain habitat is characterized by steep, exposed slopes, rocky soils and perennial vegetation including cactus, yucca, oak and juniper. See Miller et al. (2009) for a full description of the study area.

Tree cholla $(O$. imbricata $)$ are native to the southwestern USA and common throughout New Mexico, southern Colorado and southwest Texas (Benson 1982). Tree cholla are arborescent cacti with cylindrical segments (photosynthetic stems) and large, conspicuous spines. 
Tree cholla initiate new vegetative segments and flower primordia from specialized axillary buds at the terminal ends of stem segments (Miller, Tenhumberg \& Louda 2008). In central New Mexico, vegetative growth occurs from May to August, and flowering occurs in June. Nearly all plants produce vegetative segments each year, but only plants of a sufficiently large size also produce flower buds. These plants require at least 9 years of vegetative growth prior to the onset of reproduction (Miller 2007).

Like other EFN-bearing cacti, EFNs are limited to developing vegetative segments and reproductive structures (flowerbuds and, later, ripening fruits) (Blom \& Clark 1980; Oliveira et al. 1999). Note that EFNs on reproductive structures are distinct from floral nectaries, which are not considered here. Collection of floral nectar by ants is very rare, likely due to ant-repellent floral volatiles (J.R. Ohm \& T.E.X. Miller, unpubl. data). Tree cholla cacti in this area are visited predominantly by two ground-nesting ant species: the Myrmicine Crematogaster opuntiae Buren and the Dolichoderine Liometopum apiculatum Mayr. Other ant species occur on tree cholla at very low frequencies (unpubl. data) and were not observed in this study. Crematogaster opuntiae and L. apiculatum co-occur in the Los Piños environment, but do not co-occur on individual plants. Ant exclusion experiments indicated that $L$. apiculatum provided defence against insect herbivores and seed predators, but $C$. opuntiae did not (Miller 2007). The major herbivores in this system include beetles [Coleoptera: Cerambycidae], plant bugs [Hemiptera: Coreidae], weevils [Coleoptera: Curculionidae] and seed-eating moth larvae [Lepidoptera: Pyralidae] (Miller et al. 2009).

\section{ASSOCIATIONS BETWEEN PLANT DEMOGRAPHIC STATE AND ANT VISITATION}

I conducted a survey to quantify the distribution of plant sizes and reproductive states and associations of demographic state with ant occupancy. The survey was conducted on 31 May 2008 and included 250 plants that fell within a 2-m-wide, randomly positioned transect along the west-facing slope of the Los Piños mountains. For each plant, I recorded height, maximum crown width and crown width perpendicular to the maximum. These size measurements were used to calculate plant volume $\left(\mathrm{cm}^{3}\right)$ based on the volume of a cone, with the mean of maximum and perpendicular crown width as the diameter (Miller et al. 2009). I use the natural logarithm of plant volume as the size variable throughout this paper. I also recorded whether the plant was vegetative or reproductive ( $>0$ flower buds). If no ants were observed, the plant was recorded as 'vacant'. If any ants were observed, the plant was assigned to the species observed (C. opuntiae or L. apiculatum).

\section{NATURAL VARIATION IN EFN QUANTITY AND QUALITY}

\section{Field surveys}

Extrafloral nectar samples were collected from 2 June 2009 to 11 June 2009. The collections included plants that were distributed across $630 \times 30 \mathrm{~m}$ spatial blocks spanning an area of approximately $2 \mathrm{~km}^{2}$. Within blocks, plants were selected non-randomly to maximize representation of different sizes and reproductive states (vegetative or flowering). Collecting EFN required that I first prevent ants from accessing nectaries. In the evening before collection, plants were sprayed with the insecticide carbaryl at a dilution $(1.95 \mathrm{~mL}$ active ingredient $\mathrm{L}^{-1} \mathrm{H}_{2} \mathrm{O}$ ) that is $1 / 4$ the recommended concentration. In previous work, I found that this was the minimum concentration required to effectively exclude ants (Miller 2007). While the insecticide application was targeted primarily at ants, it is likely that other nectar feeding insects were similarly deterred. The time of insecticide spraying was recorded for each plant. I revisited the plants between 6 and 10 am the next morning (again recording time for each plant) and collected EFN that had accumulated overnight in $5-\mu \mathrm{L}$ microcapillary tubes. For all plants, EFN was collected from four vegetative segments (or the maximum number of segments if less than four); to randomize segment selection, I used those most consistent with the four cardinal directions. I measured the length of each stem segment and collected all EFN produced across all nectaries of the segment. EFN volume was estimated based on the length of the microcapillary tube that was filled with EFN and the inner diameter of the tube. I used an independently fit linear regression to predict the number of nectaries on a stem segment as a function of its length (nectaries $=12.58+3.13 \times \mathrm{cm}$, $\left.F_{1,98}=202.2, P<0.0001, R^{2}=0.67\right)$. These data allowed me to estimate the rate of EFN production as $\mu \mathrm{L}$ nectary ${ }^{-1} h^{-1}$. For each plant, the EFN from all stem segments was pooled into one microcentrifuge tube and stored at $-20{ }^{\circ} \mathrm{C}$.

For reproductive plants, I made additional collections of EFN produced by flower buds. As above, EFN was collected from the four flower buds (or the maximum number of buds if less than four) most consistent with the four cardinal directions. The total EFN volume accumulated on each flower bud was collected and quantified. The number of nectaries on a flower bud was not significantly related to flower bud diameter $\left(F_{1,100}=2.36, P=0.12\right)$. I therefore used the mean number of nectaries per flower bud $(23.55, n=100)$ to estimate the rate of EFN production $\left(\mu \mathrm{L}\right.$ nectary ${ }^{-1} h^{-1}$ ). As above, EFN from all flower buds of a single plant was pooled into one sample tube and stored until biochemical analysis. In total, I recorded data and collected stem segment nectar from 135 plants. In addition, I collected flower bud nectar from 49 of these plants that were reproductive. I measured the size of each plant as above and counted total numbers of stem segments and flower buds.

\section{High-performance liquid chromatography analyses of EFN composition}

Concentrations of $\mathrm{CH}$ in the nectar samples were quantified using HPLC. This analysis was conducted by the Analytical Laboratory and Research Facility in the Department of Biological Sciences at Florida State University (Tallahasee, FL, USA) following methods described in Kang et al. (2007). Briefly, nectar samples were diluted then injected into a Waters 2695 Alliance Separation Module (Waters Co., Milford, MA, USA). The mobile phase was $150 \mathrm{~mm} \mathrm{NaOH}$ running at a speed of $1 \mathrm{~mL} \min ^{-1}$. The detector was an ESA Coulochem II electrochemical detector with a gold electrode (ESA Biosciences Inc., Chelmsford, MA, USA). Peaks were identified by comparing retention times with those of standard sugars (glucose, fructose and sucrose). Internal standards were added to the nectar subsamples before injection. In total, I analysed the carbohydrate content of stem segment EFN from 84 plants; for 37 of these that were reproductive, I also analysed their flower bud EFN.

I used HPLC to quantify amino acid composition for a subset of the samples $(n=53$, including 40 samples of stem segment EFN and an additional 13 samples of flower bud nectar from plants that were reproductive). The amino acid analysis was performed by the Protein Chemistry Laboratory at Texas A\&M University (College Station, TX, USA) using a Hewlett-Packard 1090 HPLC. The AAs were detected by a fluorometric detector (HP1046A) by monitoring the primary AAs, derivatized with OPA (Agilent Technologies, Santa Clara, CA, USA, \#5061-3335) at excitation/emission $340 / 450 \mathrm{~nm}$, and the 
secondary AAs were tagged with FMOC (Agilent Technologies part \#5061-3337) at 266/305 nm. The separation used two solvents. Solvent A was a $20 \mathrm{~mm} \mathrm{Na}$ acetate buffer with $0.018 \% \mathrm{v} / \mathrm{v}$ triethylamine, $0.05 \mathrm{~mm}$ EDTA, and $0.3 \%$ tetrahydrofuran adjusted to $\mathrm{pH} 7.2$ with weak acetic acid. Solvent B was a $20 \% 100 \mathrm{~mm}$ Na acetate buffer with $40 \%$ acetonitrile and $40 \%$ methanol. The working gradient began at $0 \mathrm{~min}$ at $100 \% \mathrm{~A}$ at $0.45 \mathrm{~mL} \mathrm{~min}^{-1}$ and went to $60 \% \mathrm{~B}$ over $17 \mathrm{~min}$. The assays were calibrated by $5 \mathrm{nmol}$ standards (Agilent Technologies part \#5061-3331) and normalized with $5 \mathrm{nmol}$ of two internal standards: Norvaline for the primary AAs and sarcosine for the secondary AAs added directly to the samples.

\section{STATISTICAL ANALYSES}

\section{Associations between demographic state and ant occupancy}

To test for associations between plant size/stage and ant visitation, I first fit a generalized linear model (GLM) with presence/absence of any ants as a binomial response variable. I used chi-squared tests of likelihood ratios between nested models to test whether the probability of 'vacancy' was significantly related to plant size $\left[\log \left(\mathrm{cm}^{3}\right)\right]$, reproductive state (vegetative or reproductive) or both (as additive or interacting factors). Secondly, for the subset of plants that were occupied by ants, I fit the same set of models for the probability of occupancy by L. apiculatum. Because there were only two ant species, the complement of $\operatorname{Pr}(L$. apiculatum $)$ equals $\operatorname{Pr}(C$. opuntiae $)$. For both analyses, I first fit a null model (no effects of size or reproduction) and compared the fits of increasingly complex models. These and all following analyses were conducted in R v.2.15.1 (R Core Development Team 2012).

\section{Extrafloral nectar quantity}

I used generalized linear mixed models [package 'LME4' (Bates, Maechler \& Bolker 2012)] to test effects of plant size on EFN secretion and to test for differences in secretion rates between nectaries on flower buds vs. stem segments. There were many observations of zero EFN produced, leading to a skewed distribution of EFN production. Therefore, I first fit a binomial model testing effects of size and nectary type on the presence/absence of EFN. To account for the hierarchical nature of the data (there were multiple observations of each nectary type within each plant), individual plant and individual structure (stem segment or flower bud) within plant were included as random effects. I used chi-squared tests of likelihood ratios between nested models to determine whether including plant size, nectary type and their interaction improved prediction of EFN production over a null model with only random variation among plants and structures within plants. Then, for the subset of the data with nonzero EFN production, I fit a second, Gaussian model to test effects of plant size and nectary type on the natural log-transformed rate of EFN production $\left(\mu \mathrm{L}\right.$ nectary $\left.{ }^{-1} \mathrm{~h}^{-1}\right)$. As above, I included random effects of plant and structure within plant and used likelihood ratio tests to identify the best-fitting model.

To more directly examine differences between stem segment and flower bud EFN production within individual plants, I calculated mean EFN production ( $\mu \mathrm{L}$ nectary ${ }^{-1} \mathrm{~h}^{-1}$ ) of stem segment nectaries and flower bud nectaries, where the means were taken over the relevant structures within an individual reproductive plant. For each plant, I calculated the within-individual difference (flower bud EFN-stem segment EFN) and tested whether these deviated significantly from zero using a $t$-test.
I next examined EFN secretion from stem segment nectaries on vegetative vs. flowering plants. As above, due to the distribution of the data, I conducted the analysis in two steps. First, I tested whether plants that were vegetative vs. reproductive differed in their probability of producing any EFN from stem segment nectaries. I fit a binomial model in which plant and stem segment within plant were random factors, reproductive status was a fixed factor, and presence/ absence of stem segment EFN was the response variable. Because vegetative and reproductive plants occupied overlapping but different regions of the size distribution, and because the probability of EFN production increased with plant size (Results), this analysis was limited to include only plants larger than the smallest reproductive size and smaller than the largest vegetative size; this restriction decoupled reproductive status from the potentially confounding effect of size. I used likelihood ratio tests to determine whether adding plant reproductive status improved the fit of a null model. For the subset of the stem segment data with nonzero EFN production, I fit a second mixed-effects model to ask whether the rate of EFN production $\left(\mu \mathrm{L}\right.$ nectary ${ }^{-1} \mathrm{~h}^{-1}$ ) from stem segments differed between vegetative and reproductive plants. I used a likelihood ratio test to compare models with and without plant reproductive status as a fixed explanatory variable, including random variation among plants and among stem segments within plants.

\section{Extrafloral nectar quality}

Next, I tested whether plant size and reproductive state modified the concentrations (nmol $\mu \mathrm{L}^{-1} \mathrm{EFN}$ ) of $\mathrm{CHs}$ and $\mathrm{AAs}$ in tree cholla EFN. For both response variables, I used a mixed-effects model with plant size and nectary type as fixed effects and individual plant as a random effect. Concentrations were natural log-transformed, which stabilized the residual variance with respect to fitted values. I did not include structure within plant as a random effect because EFN samples were pooled among nectary types within plants. However, this analysis retained plant as a random effect because there were often multiple observations (stem segment and flower bud EFN) within each individual. I used likelihood ratio tests to determine whether including plant size and/or nectary type improved fit over a null model with only random variance across plants. At the within-plant level, I tested whether differences in $[\mathrm{CH}]$ and $[\mathrm{AA}]$ of stem segment and flower bud EFN from reproductive plants deviated from zero using a $t$-test. I also tested whether $[\mathrm{CH}]$ and $[\mathrm{AA}]$ of stem segment EFN differed between vegetative and reproductive plants. As only stem segment data were included in this analysis, there was one observation per individual for both response variables, and I therefore used $t$-tests to compare the natural log-transformed concentrations from vegetative and reproductive plants.

For $\mathrm{CH}$ composition, I tested whether the relative abundance of monosaccharide (glucose and fructose) vs. disaccharide (sucrose) $\mathrm{CH}$ differed with respect to plant size and reproductive state. As above, I fit mixed models, accounting for multiple observations within individuals and asked whether accounting for plant size or nectary type improved prediction of the proportion of the total sugars made up of sucrose; the proportion data were acrsin-square root-transformed, which stabilized variances. Within reproductive plants, I conducted a $t$-test on the difference in the proportion of sucrose between stem segment and flower bud nectaries. Finally, I used a $t$-test to compare the proportion of sucrose between the stem segment EFN of vegetative vs. reproductive plants.

High-performance liquid chromatography analysis of tree cholla EFN yielded information on the abundances of 19 free AAs. I used 
non-metric multidimensional scaling (NMDS) to distil relative abundance data into fewer axes of variation [package 'VEGAN' (Oksanen 2012)]. I used a Bray-Curtis distance matrix and searched for the minimum number of NMDS axes that led to the maximum reduction in stress. Two dimensions reduced stress to 0.14 and yielded an $R^{2}$ of 0.938. I therefore used values from these two ordination axes in mixed models to test for variation in AA composition with respect to size and reproductive state. To contrast stem segment and flower bud EFN composition within plants, I tested whether the within-plant differences for values on both NMDS axes deviated from zero using $t$ tests. Finally, I used $t$-tests to compare NMDS values between stem segment EFN from vegetative and reproductive plants.

\section{Extrapolating EFN traits to the whole-plant scale}

The data and analyses described above allowed me to quantify variation in EFN traits of individual nectaries, the scale at which they were measured. As plants grow, the total number of stem segments and flower buds (and hence the total number of nectaries) increases, and the allocation of meristematic tissues shifts towards greater relative abundance of flower buds (Miller, Tenhumberg \& Louda 2008). Consequently, understanding how nectary-level EFN traits affect mutualist rewards at the whole-plant level requires accounting for the total number and types of nectaries. Because a single ant species (and likely a single colony: Lanan \& Bronstein 2013) occupies a single plant at the exclusion of others, the whole plant is the appropriate scale at which to assess partner quality from the ants' perspectives.

For EFN quantity, I extrapolated nectary-level EFN production $\left(\mu \mathrm{L}\right.$ nectary ${ }^{-1} \mathrm{~h}^{-1}$ ) to the plant level by multiplying estimates for each nectary type by the total numbers of stem segment nectaries and flower bud nectaries on each plant and summing over nectary types. For EFN quality, I calculated average whole-plant trait values $(\mathrm{CH}$ and AA concentration and composition) as the weighted means of stem segment and flower bud nectary-level trait values, weighting by the relative abundances of nectary types on each plant. Total number of stem segments nectaries was estimated for each plant with the regression for nectary number vs. stem segment length (see Field surveys) using the mean length of the four sampled stem segments and multiplying by the total number of stem segments. Total number of flower bud nectaries was the product of the mean number of nectaries per flowerbud (see Field surveys) and the total number of flower buds. I fit generalized linear models and used model selection methods described above to characterize the dependence of plant-level EFN traits on plant size and reproductive state [vegetative or reproductive ( $>0$ flower buds)]. For the whole-plant analysis, I analysed only traits that varied with respect to plant size and/or nectary type at the nectary level (otherwise, nectary-level traits are representative of the whole-plant average). Note that errors in the estimation of nectary-level traits were propagated through the whole-plant analysis. For this reason, I focus on relative effects of plant size and reproductive state; absolute values should be interpreted cautiously.

\section{Results}

\section{ASSOCIATIONS OF PLANT DEMOGRAPHIC STATE WITH ANT VISITATION}

The tree cholla size and stage distribution (Fig. 1a) was characteristic of long-lived perennial plants: most individuals in the population were vegetative, and relatively few, large individuals were reproductive. The size distribution was dominated
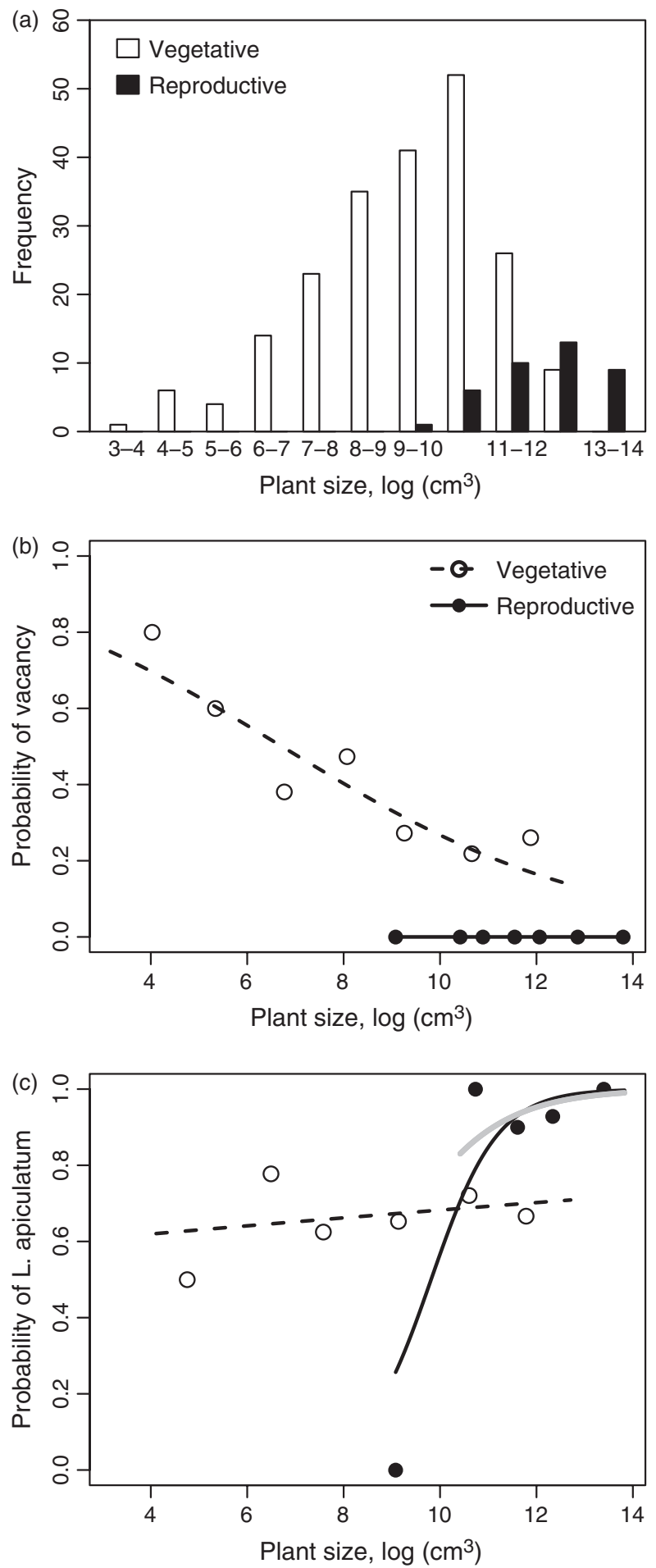

Fig. 1. (a) Histogram of plant sizes, separated by reproductive states. (b) Probability of 'vacancy' (no ant visitation) in relation to plant size and reproductive state. (c) Probability of occupancy by Liometopum apiculatum in relation to plant size and reproductive state. The complement of $\operatorname{Pr}(L$. apiculatum $)$ gives $\operatorname{Pr}($ Crematogaster opuntiae $)$. Lines show best-fit models. In b and c, observations of 'successes' and 'failures' are binned over size intervals to show proportions of plants in each bin. In c, the grey line shows the best-fit model for reproductive plants with one outlier removed. 
by intermediate sizes, with few plants that were very small or very large, consistent with infrequent recruitment, high survival of established plants and slow growth rates (Miller et al. 2009).

Ant visitation and partner identity were significantly related to plant size and reproductive state. The probability of vacancy declined with size for vegetative plants and was zero for reproductive plants of any size (Fig. 1b; null model vs. model with size + reproductive state: $\chi^{2}=41.6$, d.f. $=2$, $P<0.0001$ ). Among plants that were not vacant, probabilities of occupancy by Liometopum increased and by Crematogaster decreased significantly with size for both vegetative and reproductive plants (Fig. 1c). There was support for a model with interactive effects of size and reproductive state (additive model vs. interaction model: $\chi^{2}=5.0$, d.f. $=1, P<0.025$ ), although this was heavily influenced by a single, unusually small reproductive plant that was occupied by Crematogaster [filled point at $\operatorname{Pr}($ Liom. $)=0$ in Fig. 1c]. With this observation excluded, the interaction model did not provide a better fit than the additive model $\left(\chi^{2}=0.94\right.$, d.f. $\left.=1, P<0.33\right)$. Generally, reproductive plants were associated non-randomly (almost exclusively) with Liometopum relative to vegetative plants.

\section{NATURAL VARIATION IN EFN QUANTITY AND QUALITY}

\section{Extrafloral nectar quantity}

At the level of individual nectaries, there was significant variation in the probability and amount of EFN production among plants of different sizes and between vegetative vs. reproductive nectaries within plants. The probability of secreting any EFN was significantly related to plant size and nectary type (null model vs. size*nectary type interaction: $\chi^{2}=50.02$, d.f. $=3, \quad P<0.0001)$. The likelihood of EFN secretion increased with size, and flower bud nectaries were 10-20\% more likely to secrete EFN than stem segment nectaries for a plant of a given size (Fig. 2a). For plants that produced EFN, there was no effect of plant size on the rate of EFN secreted by either stem segments or flower buds (Fig. 2b). However, there was a significant difference in EFN rate between structures (null model vs. main effect of nectary type: $\chi^{2}=53.86$, d.f. $=1, P<0.0001$ ), with flower buds nectaries secreting EFN at a rate more than $3 \times$ that of stem segment nectaries (flower bud mean $=2.82 \times 10^{-3} \mu \mathrm{L}$ nectary ${ }^{-1} \mathrm{~h}^{-1}$, stem segment mean $=8.64 \times 10^{-4} \mu \mathrm{L}$ nectary ${ }^{-1} \mathrm{~h}^{-1} ; \quad$ Fig. $2 \mathrm{~b}$ ). The difference in EFN rate was also apparent in the contrast (a)
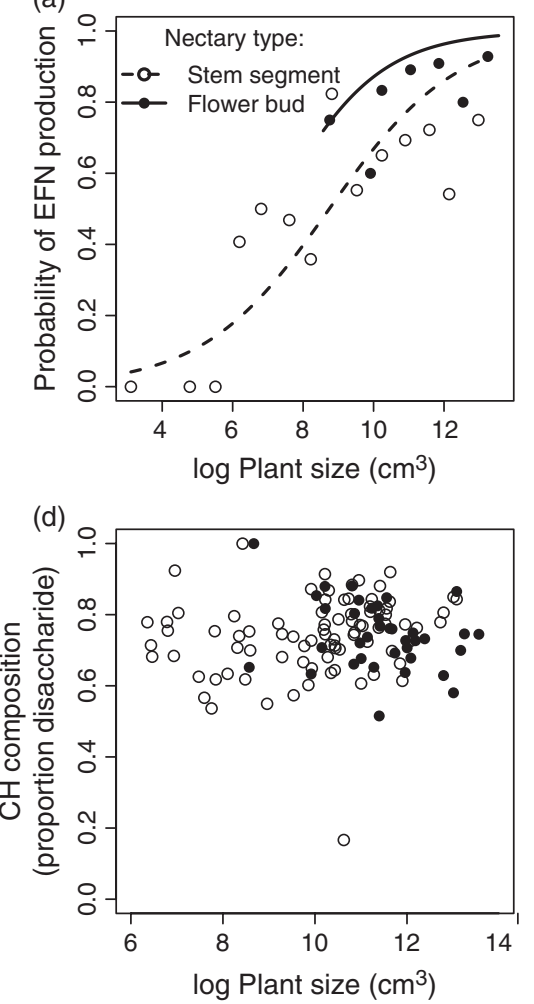

(b)

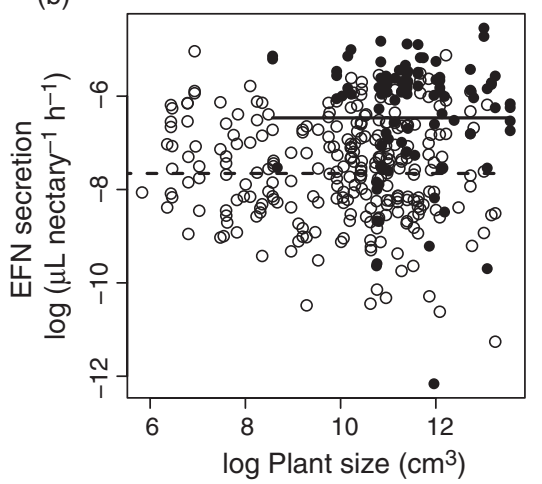

(e)

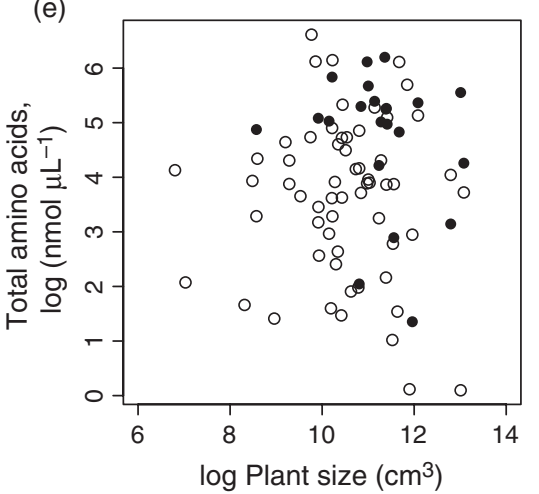

(c)

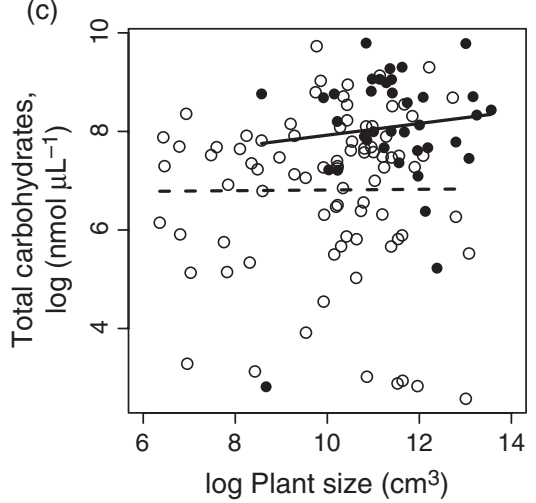

(f)

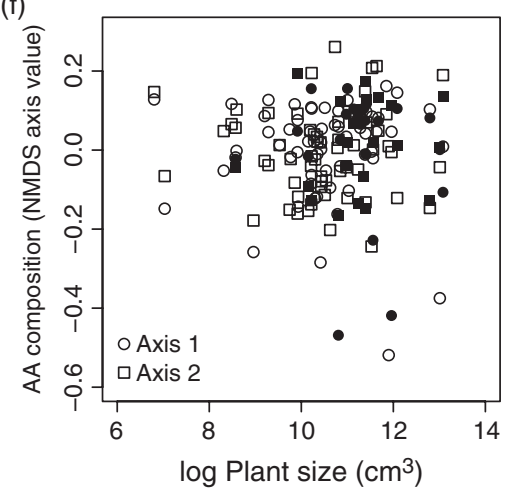

Fig. 2. Variation in extrafloral nectar (EFN) traits at the scale of individual nectaries with respect to plant size and nectary type: (a) the probability of producing any EFN, (b) the rate of EFN secretion $\left(\mu \mathrm{L}\right.$ nectary ${ }^{-1} \mathrm{~h}^{-1}$ ) for plants with nonzero EFN production, (c) the concentration of total carbohydrates (nmol $\mu \mathrm{L}^{-1} \mathrm{EFN}$ ), (d) the relative abundance of disaccharide vs. monosaccharide sugars, (e) the concentration of total free amino acids (nmol $\mu \mathrm{L}^{-1} \mathrm{EFN}$ ) and (f) the amino acid composition, represented as values from two ordination axes. All panels show stem segment nectaries (filled shapes) and flower bud nectaries (open shapes). Lines, when present, show significant effects of size and/or nectary type from fitted mixed-effect models (dashed = stem segment, solid = flower bud), which account for the non-independence of multiple observations within individual plants. In (a), presence/absence data are binned over size intervals to show the proportion of nectaries producing EFN. 
between nectary types within individual reproductive plants (Fig. 3a, $t_{43}=5.92, P<0.001$ ).

While there were strong differences between nectary types, there was no evidence that reproduction modified EFN secretion by stem segment nectaries. The probability of EFN secretion did not differ between stem segment nectaries on plants that were vegetative vs. reproductive $\left(\chi^{2}=0.044\right.$, d.f. $=1, P<0.83$ ). Similarly, the rate of EFN secretion from stem segment nectaries did not differ between vegetative and reproductive plants $\left(\chi^{2}=0.01\right.$, d.f. $\left.=1, P<0.99\right)$.

\section{Extrafloral nectar quality: carbohydrates}

The $\mathrm{CH}$ concentration of cactus EFN was affected by the interaction of nectary type and plant size (null model vs. size*nectary type: $\chi^{2}=27.18$, d.f. $\left.=2, P<0.0001\right)$. Flower bud nectaries produced nectar with a greater carbohydrate concentration, on average, than stem segment nectaries, and the carbohydrate concentration of flower bud nectar, but not stem segment nectar increased with plant size (Fig. 2c). Greater $\mathrm{CH}$ concentration of flower bud nectar was also apparent in within-plant comparisons, with flower bud nectaries producing $22 \%$ more $\mathrm{CH}$ (Fig. $3 \mathrm{~b} ; t_{24}=-4.5, P<0.001$ ).
However, there was no difference in $\mathrm{CH}$ concentration of stem segment EFN from vegetative vs. reproductive plants $\left(t_{49.7}=0.05, P<0.96\right)$.

The relative abundance of disaccharide vs. monosaccharide CHs did not vary significantly with plant size or nectary type across plants (Fig. 2d). However, there was a difference between nectary types in paired samples from individual reproductive plants: stem segment EFN had greater relative abundance of disaccharide $\mathrm{CH}$ (mean proportion $=0.79$ ) than flower bud $\mathrm{EFN}$ (mean proportion $=0.73 ; t_{24}=-3.05$, $P<0.005$; Fig. 3c). Finally, there was a significant difference in relative abundance of disaccharide $\mathrm{CHs}$ between vegetative and reproductive plants $\left(t_{81.4}=-3.8, P<0.001\right)$. Interestingly, this difference was in the opposite direction to the vegetative/reproductive nectary contrast within individuals: stem segment EFN from reproductive plants had greater relative abundance of disaccharide (mean proportion $=0.79$ ) than stem segment EFN from vegetative plants (mean proportion $=0.71$ ).

\section{Extrafloral nectar quality: amino acids}

A null model including only random plant-to-plant variance provided the best fit to the AA concentration data, indicating
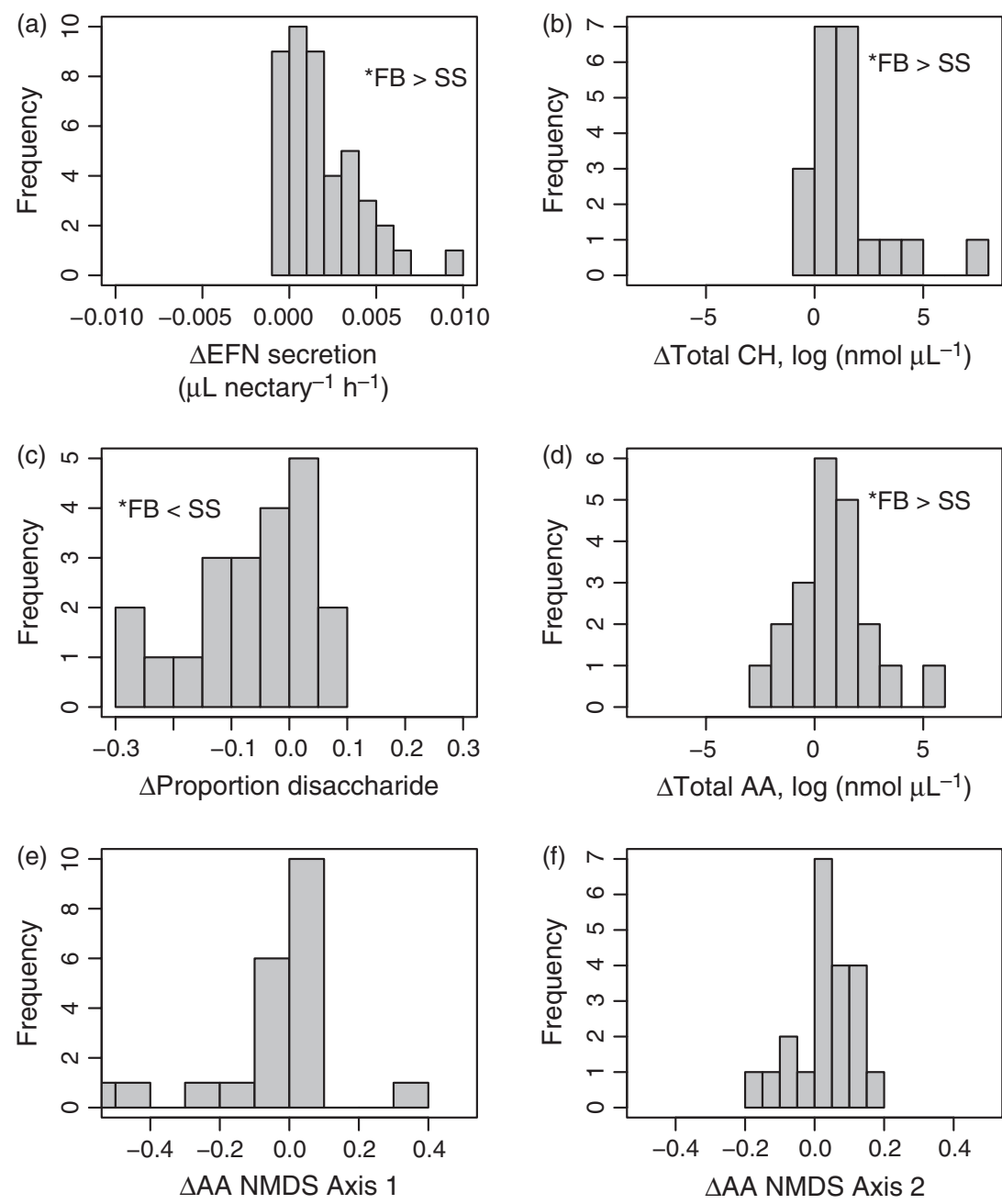
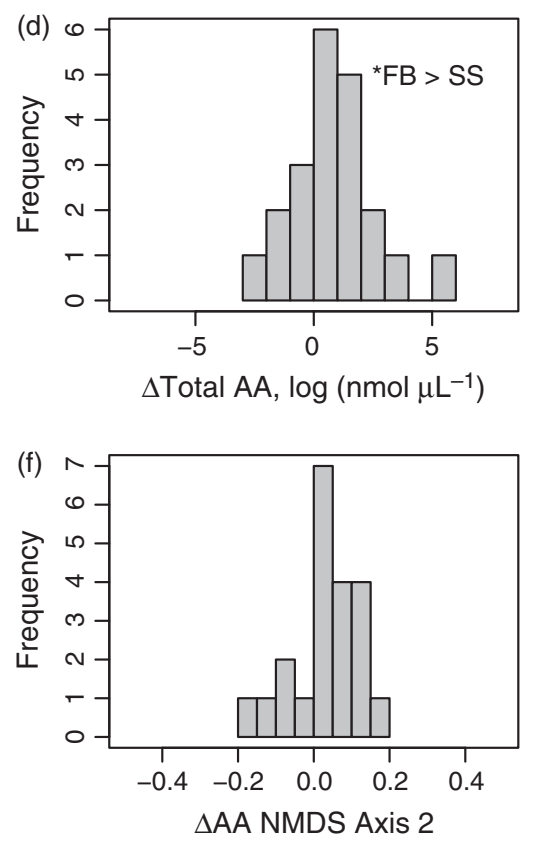

Fig. 3. Histograms of the difference $(\Delta)$ in extrafloral nectar (EFN) traits between stem segment (SS) and flower bud (FB) nectaries within individual plants. Positive values indicate that the trait value of a flower bud nectary exceeded the value of a stem segment nectary from the same plant. (a) Rate of EFN secretion, (b) concentration of total carbohydrates $(\mathrm{CH}), \quad$ (c) proportion of total $\mathrm{CHs}$ that were disaccharides, (d) concentration of total amino acids (AA), (e) and (f) values from first and second axes, respectively, of non-metric multidimensional scaling ordination. Differences that deviated significantly from zero and the directions of the differences are indicated above the histograms. 
that there were no effects of plant size or nectary type across plants (Fig. 2e). However, in paired samples within individual reproductive plants, AA concentrations were greater in flower bud vs. stem segment EFN, with flower bud EFN enriched in AAs by $30 \%$ (Fig. 3 d; $t_{20}=2.19, P<0.04$ ). Comparing across vegetative and reproductive plants, there was no difference in the AA concentration of stem segment EFN $\left(t_{49.7}=0.05, P<0.96\right)$.

There was no evidence that amino acid composition varied with plant size or reproductive state (Fig. 2f). Null models, including only random variance among plants, provided the best fit to variation along both NMDS axes. Within individual plants, the difference between stem segment and flower bud EFN did not deviate from zero for either NMDS axis (Axis 1: $t_{20}=1.47, P<0.16$, Axis $2: t_{20}=0.36, P<0.97$; Fig. 3 e, f). Finally, stem segment nectar from vegetative vs. reproductive plants did not differ in AA composition along either NMDS axis (Axis 1: $t_{78.6}=1.37, P<0.17$, Axis 2: $\left.t_{72.4}=-0.84, P<0.4\right)$.

\section{Extrapolating EFN traits to the whole-plant scale}

Nectary-level EFN traits scaled up to influence the quantity and quality of EFN produced at the whole-plant level
(Fig. 4). The probability of any EFN produced by entire plants increased with plant size $\left(\chi^{2}=30.8, \quad\right.$ d.f. $=1$, $P<0.0001)$. While larger plants were more likely to flower, reproductive state per se did not affect the probability of EFN production once size was accounted for (Fig. 4a). For plants that produced any EFN, the plant-level rate of secretion $\left(\mu \mathrm{L}\right.$ plant ${ }^{-1} \mathrm{~h}^{-1}$ ) was dependent on the interaction of size and reproductive state (null model vs. interaction model: $\chi^{2}=134.9, \quad$ d.f. $=3, \quad P<0.0001 ; \quad$ Fig. 4 b). EFN output increased with size for all plants, reflecting the increase in total number of nectaries as plants grow. However, reproductive plants secreted EFN at a greater rate, on average, and increased their rate more rapidly with size, reflecting the difference in EFN secretion between stem segment and flower bud nectaries, and the increase in reproductive allocation as plants grow (Miller, Tenhumberg \& Louda 2008).

Variation in plant-level EFN quality was dominated by the contrast between vegetative and reproductive plants. Reproductive plants produced EFN that was significantly greater in total $\mathrm{CH}$ concentration $\left(\chi^{2}=24.5\right.$, d.f. $=1, \quad P<0.0001$; Fig. 4c), following strong differences between stem segment and flower bud nectaries, but there were no effects of plant size. EFN from reproductive plants also had marginally greater relative abundance of disaccharide $\mathrm{CH}\left(\chi^{2}=0.033\right.$,
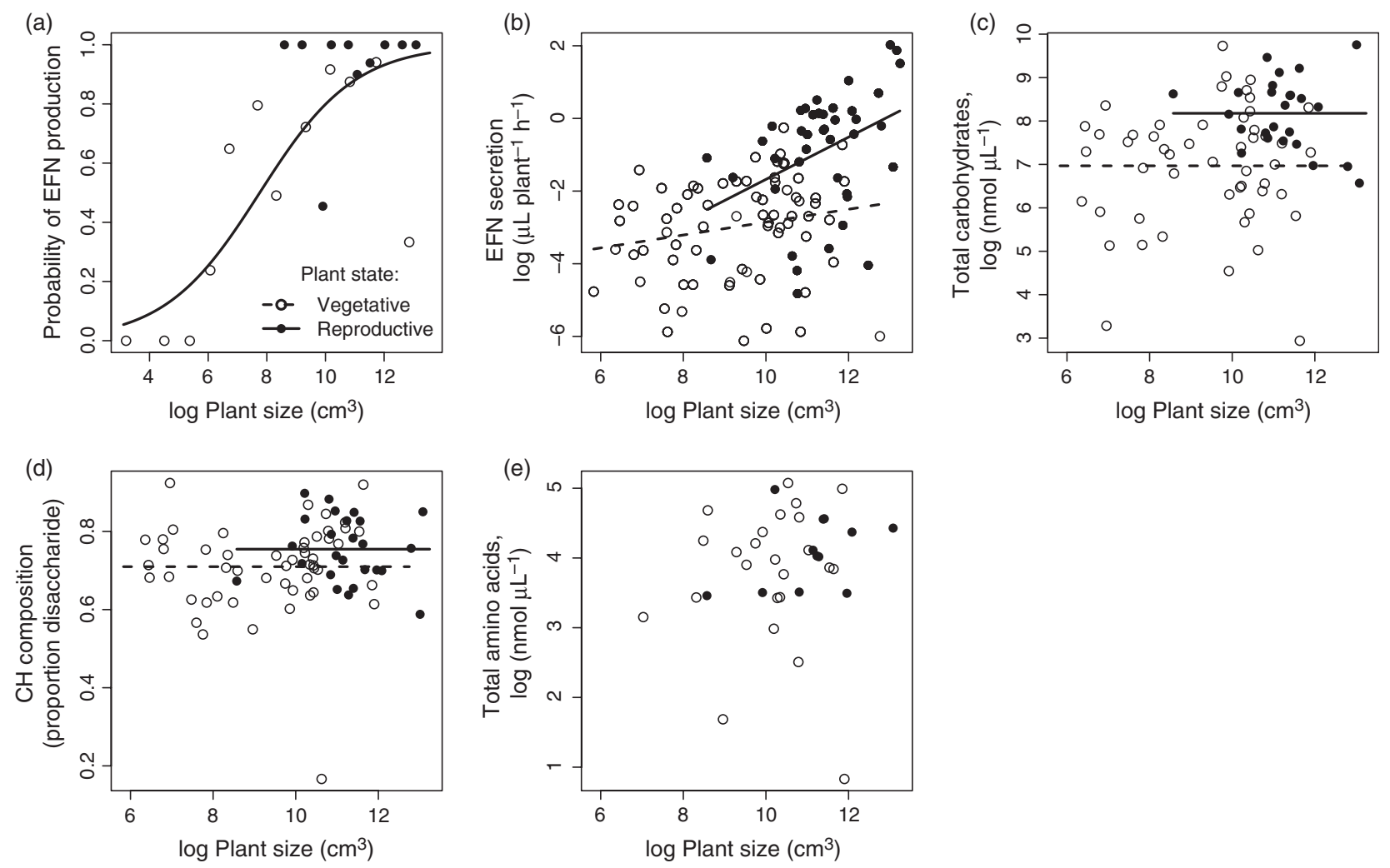

Fig. 4. Variation in extrafloral nectar (EFN) traits at the scale of entire plants with respect to plant size and reproductive state: (a) the probability of producing any EFN, (b) the rate of EFN secretion $\left(\mu \mathrm{L}\right.$ plant ${ }^{-1} \mathrm{~h}^{-1}$ ) for plants with nonzero EFN production, (c) the weighted mean concentration of total carbohydrates (nmol $\mu \mathrm{L}^{-1} \mathrm{EFN}$ ), (d) the weighted mean relative abundance of disaccharide vs. monosaccharide sugars and (e) the weighted mean of total amino acids (nmol $\mu \mathrm{L}^{-1} \mathrm{EFN}$ ). All panels show reproductive plants (filled shapes) and vegetative plants (open shapes). Lines, when present, show significant effects of size and/or plant reproductive state (dashed = vegetative, solid $=$ reproductive). In $(a)$, presence/ absence data are binned over size intervals to show the proportion of plants producing EFN. Weighted mean trait values reflect the relative abundance of stem segment and flower bud nectaries on the entire plant. 
d.f. $=1, P<0.08$; Fig. 4 c) suggesting that, at the wholeplant level, the elevated disaccharides in stem segment EFN on reproductive plants relative to vegetative plants outweighed the decrease in disaccharides in flower bud EFN relative to stem segment EFN. There were no detectable effects of plant size or reproductive state on AA concentration (Fig. 4e).

A summary of variation in EFN quantity and quality with respect to plant size and nectary type at the nectary scale, and to plant size and reproductive state at the whole-plant scale, is provided in Table 1 .

\section{Discussion}

Previous studies have documented variation in EFN traits associated with various measures of ontogeny: leaf age (Heil et al. 2000; Miller, Legaspi \& Legaspi 2010); plant size or age (e.g. Trager \& Bruna 2006); vegetative vs. reproductive plant stages (e.g. Villamil, Marquez-Guzman \& Boege 2013); and vegetative vs. reproductive organs within reproductive plants (e.g. Wäckers \& Bonifay 2004; Shenoy et al. 2012). To my knowledge, this is the first study to integrate multiple components of EFN quantity and composition over multiple dimensions of ontogenetic variation and connect them to patterns of ant-plant interactions in the field. I found that EFN traits at the level of individual nectaries varied significantly with plant size and nectary type. Furthermore, nectary-level variation scaled up to affect rewards at the whole-plant level, such that the total quantity and quality of EFN provided to ant partners depended on a plant's demographic state (size, reproductive status and their interaction). Finally, there were significant associations between plant demographic state and ant visitation, suggesting that demographic variation in EFN rewards can modify ant-plant interactions. Demographic structure is central to most studies of plant population dynamics but is rarely explicitly considered in the context of plant-animal mutualisms (Miller \& Rudolf 2011). The results of this study identify plant demographic structure as an important source of variation in rewards, with implications for plant defence and the ecological dynamics of multispecies mutualisms.

In general, variation in EFN quantity was explained by a combination of plant size and reproductive state, whereas variation in EFN composition was dominated by reproductive state alone. However, there were complex details underlying these general trends stemming from interactions between size and state, the traits affected, and the scales at which effects were manifest. At the scale of individual nectaries, the probability of producing any EFN showed the greatest variation with respect to size and was additionally greater for reproductive vs. vegetative nectaries. By contrast, the rate of secretion for nectaries with nonzero EFN differed between nectaries on vegetative vs. reproductive structures but not with respect to size. Nectary type also dominated variation in EFN CHs and AAs, with weaker effects of size. The influence of reproduction was manifest in the contrast between vegetative vs. reproductive nectaries within individuals and/or between the vegetative nectaries of vegetative vs. reproductive plants, depending on the response variable. Most of these nectarylevel traits scaled up to influence various dimensions of partner quality at the whole-plant level. Thus, plant rewards clearly varied with ontogeny, but in different ways for different reward traits, at different scales and for different axes of 'ontogeny'. These results provide a nuanced perspective on how plant investment in biotic defence varies among plant structures and over the course of the life cycle.

My results are consistent with prior studies demonstrating increasing investment in traits associated with defensive mutualism as plants develop (Fiala et al. 1994; Trager \& Bruna 2006; Kwok \& Laird 2012; Villamil, Marquez-Guzman

Table 1. Summary of effects of plant size and reproductive state on EFN traits at the nectary and whole-plant scales

\begin{tabular}{|c|c|c|c|c|c|c|}
\hline & \multicolumn{4}{|l|}{ Nectary scale } & \multicolumn{2}{|c|}{ Whole-plant scale } \\
\hline & $\begin{array}{l}\text { Effect of } \\
\text { plant size }\end{array}$ & $\begin{array}{l}\text { Stem segment } \\
\text { (SS) vs. flower } \\
\text { bud (FB) nectaries } \\
\text { across plants }\end{array}$ & $\begin{array}{l}\text { Stem segment } \\
\text { (SS) vs. flower } \\
\text { bud (FB) nectaries } \\
\text { within plants }\end{array}$ & $\begin{array}{l}\text { Stem segment } \\
\text { nectaries on } \\
\text { vegetative }\left(\mathrm{SS}_{\mathrm{V}}\right) \text { vs. } \\
\text { reproductive }\left(\mathrm{SS}_{\mathrm{R}}\right) \\
\text { plants }\end{array}$ & $\begin{array}{l}\text { Effect of } \\
\text { plant size }\end{array}$ & $\begin{array}{l}\text { Vegetative }(\mathrm{V}) \text { vs. } \\
\text { reproductive }(\mathrm{R}) \\
\text { plants }\end{array}$ \\
\hline $\begin{array}{l}\text { Probability of EFN } \\
\text { production }\end{array}$ & + & $\mathrm{SS}<\mathrm{FB}$ & N/A & $\mathrm{SS}_{\mathrm{V}}=\mathrm{SS}_{\mathrm{R}}$ & + & $\mathrm{V}=\mathrm{R}$ \\
\hline $\begin{array}{l}\text { EFN rate } \\
\left(\mu \mathrm{L} \text { nectary }{ }^{-1} \mathrm{~h}^{-1}\right. \\
\left.\text { or } \mu \mathrm{L} \text { plant }^{-1} \mathrm{~h}^{-1}\right)\end{array}$ & 0 & $\mathrm{SS}<\mathrm{FB}$ & $\mathrm{SS}<\mathrm{FB}$ & $\mathrm{SS}_{\mathrm{V}}=\mathrm{SS}_{\mathrm{R}}$ & $\begin{array}{l}+(\mathrm{V}) \\
++(\mathrm{R})\end{array}$ & $\mathrm{V}<\mathrm{R}$ \\
\hline$[\mathrm{CH}]\left(\mathrm{nmol} \mu \mathrm{L}^{-1} \mathrm{EFN}\right)$ & $0(\mathrm{SS}),+(\mathrm{FB})$ & $\mathrm{SS}<\mathrm{FB}$ & $\mathrm{SS}<\mathrm{FB}$ & $\mathrm{SS}_{\mathrm{V}}=\mathrm{SS}_{\mathrm{R}}$ & 0 & $\mathrm{~V}<\mathrm{R}$ \\
\hline Proportion disaccharide & 0 & $\mathrm{SS}=\mathrm{FB}$ & $\mathrm{SS}>\mathrm{FB}$ & $\mathrm{SS}_{\mathrm{V}}<\mathrm{SS}_{\mathrm{R}}$ & 0 & $\mathrm{~V}<\mathrm{R}$ \\
\hline$[\mathrm{AA}]\left(\mathrm{nmol} \mu \mathrm{L}^{-1} \mathrm{EFN}\right)$ & 0 & $\mathrm{SS}=\mathrm{FB}$ & $\mathrm{SS}<\mathrm{FB}$ & $\mathrm{SS}_{\mathrm{V}}=\mathrm{SS}_{\mathrm{R}}$ & 0 & $\mathrm{~V}=\mathrm{R}$ \\
\hline $\begin{array}{l}\text { AA composition (NMDS } \\
\text { axes) }\end{array}$ & 0 & $\mathrm{SS}=\mathrm{FB}$ & $\mathrm{SS}=\mathrm{FB}$ & $\mathrm{SS}_{\mathrm{V}}=\mathrm{SS}_{\mathrm{R}}$ & N/A & $\mathrm{V}=\mathrm{R}$ \\
\hline
\end{tabular}

AA, amino acid; $\mathrm{CH}$, carbohydrate; EFN, extrafloral nectar; NMDS, non-metric multidimensional scaling.

Nectary types are indicated as stem segment (SS) or flower bud (FB) and plant types as vegetative (V) or reproductive (R). Subscripts indicate stem segment nectaries on vegetative $\left(\mathrm{SS}_{\mathrm{V}}\right)$ or reproductive plants $\left(\mathrm{SS}_{\mathrm{R}}\right)$. 
\& Boege 2013), raising questions about the ultimate causes of ontogenetic patterns. In some cases, resource limitation and/or architectural constraints may limit investment by young plants in rewards for defensive mutualists. For example, myrmecophytic plants may be unable to support symbiotic ant defenders until reaching a minimum size for production of domatia (Fiala et al. 1994). Villamil, Marquez-Guzman \& Boege (2013) found that structural characteristics made the EFNs of juvenile Turnera velutina physiologically incapable of secreting EFN. However, it is also important to consider selection by herbivores and the adaptive value of defences that are specific to plant stages or structures (i.e. optimal defence theory: Rhoades 1979; Wäckers \& Bonifay 2004; Holland, Chamberlain \& Horn 2009). In this system, insect herbivory is infrequent on small tree cholla, but herbivore pressure increases significantly with size/age and especially with the onset of reproduction (Miller 2007). The elevated risk of herbivory for mature plants may select for lower investment in defensive mutualism when small, given that EFN may be costly to produce (Rutter \& Rausher 2004) but yield little fitness benefit.

In addition to size-dependent EFN production, there were strong signatures of reproduction, independent of size, on EFN quantity and quality from the nectary to whole-plant scales. Cacti at reproductive life stages produce large amounts of floral nectar to attract and reward insect pollinators (Scogin 1985; McFarland, Kevan \& Lane 1989). Strong correlation between the production of floral and extrafloral nectar is probably not coincidental. Chamberlain \& Rudgers (2012) found positive correlations between floral and EFN traits across species in the genus Gossypium. They concluded that the two sets of traits covary due to common genetic and/or physiological bases. Indeed, floral and extrafloral nectaries are not physiologically different, and they share regulatory cues, including jasmonic acid (JA) (Heil 2011). Mechanisms that account for positive correlations across species may therefore also explain positive correlations across developmental stages within species. In addition to the possibility of being a 'sideeffect' of flowering, I hypothesize an adaptive value to the shift in EFN traits associated with reproduction. Increased EFN secretion can increase ant patrolling, and this could equip reproductive plants (which face elevated pressure from floral-feeding insects) with enhanced defence, purely in terms of ant numbers.

Additionally, field surveys showed that reproductive plants differed not only in ant numbers but also in ant identity, with reproductive plants being tended almost exclusively by L. apiculatum. This could further enhance defence of reproductive plants because L. apiculatum is a superior bodyguard to $C$. opuntiae (Miller 2007). Furthermore, ant tending deters tree cholla pollinators and C. opuntiae imposes a stronger pollination cost than does L. apiculatum (Ohm and Miller, unpubl. manuscript). Thus, not only is C. opuntiae a poor defender, but it may even have a net parasitic effect at reproductive life stages. Are tree cholla simply lucky to associate non-randomly with $L$. apiculatum at the life stages when this partner is most beneficial and least costly? Or are there adaptive mechanisms by which plants can 'choose' partners?
Based on the data, I suggest two possible mechanisms for an influence of EFN traits on partner identity. First, the significant increases in EFN quantity and quality associated with reproduction may allow plants to exploit the ant competitive hierarchy. Large, reproductive individuals are the most valuable plant partners but these are rare in the population and their high rate of ant occupancy (100\%) suggests that they are a limiting resource for which ants compete strongly. Liometopum apiculatum is not only a superior defender to $C$. opuntiae but also a superior competitor (Miller 2007). The high prevalence of L. apiculatum on reproductive plants could represent competitive exclusion of $C$. opuntiae. Thus, positive correlation between competitive and defensive abilities could mean that when ants compete, plants win. Secondly, the change in disaccharide content of reproductive plants may influence partner identity based on ant production of invertase, the enzyme that cleaves disaccharide sugars into monosaccharides (necessary for digestion). Co-variation across plant and ant species between EFN disaccharide content and ant invertase activity can explain partner-specific associations in ant-Acacia mutualisms (Heil, Rattke \& Boland 2005; Kautz et al. 2009). Whether a similar mechanism can explain life stage-specific associations in this system remains an open question. These hypotheses merit experimental investigation, particularly given our poor understanding of shifts in partner identity across plant life stages in other ant-plant mutualisms (Young, Stubblefield \& Isbell 1997; Fonseca \& Benson 2003; Dejean et al. 2008). Ontogenetic partner shifts have important implications for the net influence of the ant partner guild on plant fitness (Palmer et al. 2010) and for the maintenance of partner species diversity based on feedbacks between the partner guild and plant population stage structure (Lee, Miller \& Inouye 2011).

Like any observational study, alternative interpretations for the patterns I documented warrant consideration. For example, differences in EFN traits between vegetative and reproductive plants may be due not (or not entirely) to reproduction per se but to unmeasured factors (e.g. microhabitat characteristics) that independently affect plant reproduction and EFN (although, importantly, within-plant contrasts control for such effects). Similarly, associations between plant demographic state, EFN traits and ant occupant could be explained by multiple pathways of causation. In addition to the influence of EFN traits on ant identity suggested above, partner identity could affect the demographic state of the plant (Vasconcelos \& Davidson 2000), and unmeasured factors could independently affect ant identity and plant demographic state. Experimental approaches that disentangle these non-mutually exclusive hypotheses would be valuable. Furthermore, I do not know whether EFN is inducible in this system, as in other EFN-secreting cacti (Holland, Chamberlain \& Horn 2009). It is possible that past herbivory contributed to differences between vegetative and reproductive plants, because these tend to carry different herbivore loads.

In summary, my results suggest that this and likely other plant-animal mutualisms are best viewed through the lens of demography. Populations of long-lived plants are 
demographically heterogeneous - spanning sizes and reproductive states - and the rewards offered to animal mutualists can track demographic heterogeneity. The ontogenetic trajectories of individual plants include significant variation in reward quantity and quality - arising from nectary-level traits that can scale up to affect whole-plant rewards - with consequences for the strength of biotic defence over the life cycle. From the perspectives of the two ant partners, the uneven distribution of demographic states within the plant population makes for a heterogeneous resource base that could affect their individual population dynamics as well as their competitive dynamics. Through their effects on herbivores and hence plant demography, ants may also influence the distribution of demographic states, setting the stage for potentially complex feedbacks that warrant attention from empiricist and theorists.

\section{Acknowledgements}

I gratefully acknowledge field assistance from R. Berg, C. Min-Venditti, E. Gering, J. Ohm, A. Savage, R. Patterson, O. Ragni, M. Donald and K. Yule. M. Seavy, J. Johnson and D. Fiore provided valuable assistance with the HPLC analyses. S. Chamberlain and two referees provided helpful comments on the manuscript. I acknowledge the use of the Analytical Laboratory at Florida State University and the Protein Chemistry Laboratory at Texas A\&M University. This work was supported by the Sevilleta LTER (NSF DEB-0620482 and DEB-1232294) and the Godwin Assistant Professorship in the Department of Ecology and Evolutionary Biology at Rice University.

\section{References}

Ballhorn, D.J., Godschalx, A.L. \& Kautz, S. (2013) Co-variation of chemical and mechanical defenses in lima bean (Phaseolus lunatus L.). Journal of Chemical Ecology, 39, 413-417.

Barton, K.E. \& Koricheva, J. (2010) The ontogeny of plant defense and herbivory: characterizing general patterns using meta-analysis. The American Naturalist, 175, 481-493.

Bates, D., Maechler, M. \& Bolker, B. (2012) lme4: Linear mixed-effects models using S4 classes. http://CRAN.R-project.org/package=lme4.

Benson, L. (1982) Cacti of the United States and Mexico. Stanford University Press, Stanford, CA.

Blom, P.E. \& Clark, W.H. (1980) Observations of ants (Hymenoptera: Formicidae) visiting extrafloral nectaries of the barrel cactus, Ferocactus gracilis Gates (Cactaceae), in Baja California, Mexico. The Southwestern Naturalist, 25, 181-196.

Blüthgen, N. \& Fiedler, K. (2004) Preferences for sugars and amino acids and their conditionality in a diverse nectar-feeding ant community. Journal of Animal Ecology, 73, 155-166.

Boege, K. \& Marquis, R.J. (2005) Facing herbivory as you grow up: the ontogeny of resistance in plants. Trends in Ecology and Evolution, 20, 441-448.

Chamberlain, S.A. \& Rudgers, J.A. (2012) How do plants balance multiple mutualists? Correlations among traits for attracting protecting bodyguards and pollinators in cotton (Gossypium). Evolutionary Ecology, 26, 65-77.

Dejean, A., Djieto-Lordon, C., Crerghino, R. \& Leponce, M. (2008) Ontogenetic succession and the ant mosaic: an empirical approach using pionee trees. Basic and Applied Ecology, 9, 316-323.

Djieto-Lordon, C., Dejean, A., Gibernau, M., Hossaert-McKey, M. \& McKey, D. (2004) Symbiotic mutualism with a community of opportunistic ants: protection, competition, and ant occupancy of the myrmecophyte Barteria nigritana (Passifloraceae). Acta Oecologica, 26, 109-116.

Fiala, B., Grunsky, H., Maschwitz, U. \& Linsenmair, K.E. (1994) Diversity of ant-plant interactions: protective efficacy in Macaranga species with different degrees of ant association. Oecologia, 97, 186-192.

Fonseca, C.R. \& Benson, W.W. (2003) Ontogenetic succession in Amazonian ant tress. Oikos, 102, 407-412.

Gonzalez-Teuber, M. \& Heil, M. (2009) The role of extrafloral nectar amino acids for the preferences of facultative and obligate ant mutualists. Journal of Chemical Ecology, 35, 459-468.
Heil, M. (2011) Nectar: generation, regulation and ecological functions. Trends in Plant Science, 16, 191-200.

Heil, M., Rattke, J. \& Boland, W. (2005) Postsecretory hydrolysis of nectar sucrose and specialization in ant/plant mutualism. Science, 308, 560-563.

Heil, M., Fiala, B., Baumann, B. \& Linsenmair, K.E. (2000) Temporal, spatial and biotic variations in extrafloral nectar secretion by Macaranga tanarius. Functional Ecology, 14, 749-757.

Holland, J.N., Chamberlain, S.A. \& Horn, K.C. (2009) Optimal defence theory predicts investment in extrafloral nectar resources in an ant-plant mutualism. Journal of Ecology, 97, 89-96.

Holland, J.N., Chamberlain, S.A. \& Miller, T.E.X. (2011) Consequences of ants and extrafloral nectar for a pollinating seed-consuming mutualism: ant satiation, floral distraction, or plant defense? Oikos, 120, 381-388.

Kang, Y., Outlaw, W.H., Fiore, G.B. \& Riddle, K.A. (2007) Guard cell apoplastic photosynthate accumulation corresponds to a phloem-loading mechanism. Journal of Experimental Botany, 58, 4061-4070.

Kautz, S., Lumbsch, H.T., Ward, P.S. \& Heil, M. (2009) How to prevent cheating: a digestive specialization ties mutualistic plant-ants to their ant-plant partners. Evolution, 63, 839-853.

Koptur, S. (1992) Extrafloral nectary-mediated interactions between insects and plants. Insect-Plant Interactions, Vol. 4 (ed. E.A. Bernays), pp. 81-130. CRC Press Inc, Boca Raton, FL, USA.

Kost, C. \& Heil, M. (2005) Increased availability of extrafloral nectar reduces herbivory in Lima bean plants (Phaseolus lunatus, Fabaceae). Basic and Applied Ecology, 6, 234-248

Kwok, K.E. \& Laird, R.A. (2012) Plant age and the inducibility of extrafloral nectaries in Vicia faba. Plant Ecology, 213, 1823-1832.

Lanan, M.C. \& Bronstein, J.L. (2013) An ant's-eye view of an ant-plant protection mutualism. Oecologia, 172, 779-790.

Lee, C.T. \& Inouye, B.D. (2010) Mutualism between consumers and their shared resources can promote competitive coexistence. The American Naturalist, 175, 277-288

Lee, C.T., Miller, T.E.X. \& Inouye, B.D. (2011) Consumer effects on the vital rates of their resource can determine the outcome of competition between consumers. The American Naturalist, 178, 452-463.

Marazzi, B., Bronstein, J.L. \& Koptur, S. (2013) The diversity, ecology and evolution of extrafloral nectaries: current perspectives and future challenges. Annals of Botany, 111, 1243-1250.

McFarland, J.D., Kevan, P.G. \& Lane, M.A. (1989) Pollination biology of Opuntia imbricata (Cactaceae) in southern Colorado. Canadian Journal of Botany, 67, 24-28.

Miller, T.E.X. (2007) Does having multiple partners weaken the benefits of facultative mutualism? A test with cacti and cactus-tending ants. Oikos, 116, 500-512.

Miller, T.E.X., Legaspi, J.C. \& Legaspi, B. (2010) Experimental test of biotic resistance to an invasive herbivore provided by potential plant mutualists. Biological Invasions, 12, 3563-3577.

Miller, T.E.X. \& Rudolf, V.H.W. (2011) Thinking inside the box: communitylevel effects of stage-structured populations. Trends in Ecology and Evolution, 25, 457-466.

Miller, T.E.X., Tenhumberg, B. \& Louda, S.M. (2008) Herbivore-mediated ecological costs of reproduction shape the life history of an iteroparous plant. The American Naturalist, 171, 141-149.

Miller, T.E.X., Louda, S.M., Rose, K.A. \& Eckberg, J.O. (2009) Impacts of insect herbivory on cactus population dynamics: experimental demography across an environmental gradient. Ecological Monographs, 79, 2009.

Ness, J.H., Morris, W.F. \& Bronstein, J.L. (2006) Integrating quality and quantity of mutualistic service to contrast ant species protecting Ferocactus wislizeni. Ecology, 87, 912-921.

Ness, J.H., Morris, W.F. \& Bronstein, J.L. (2009) For ant-protected plants, the best defense is a hungry offense. Ecology, 90, 2823-2831.

Ohnmeiss, T.E. \& Baldwin, I.T. (2000) Optimal defense theory predicts the ontogeny of an induced nicotine defense. Ecology, 81, 1765-1783.

Oksanen, J., Blanchet, F.G., Kindt, R., Legendre, P., Minchin, P.R., O'Hara, R.B., Simpson, G.L., Solymos, P., Stevens, M.H.H. \& Wagner, H. (2012) vegan: Community Ecology Package. http://CRAN.R-project.org/ package $=$ vegan .

Oliveira, P.S., Rico-Gray, V., Diez-Castelazo, C. \& Castillo-Guevara, C. (1999) Interactions between ants, extrafloral nectaries, and insect herbivores in Neotropical sand dunes: herbivore deterrence by visiting ants increases fruit set in Opuntia stricta (Cactaceae). Functional Ecology, 13, 623-631.

Palmer, T.M., Doak, D.F., Stanton, M.L., Bronstein, J.L., Kiers, E.T., Young, T.P., Goheen, J.R. \& Pringle, R.M. (2010) Synergy of multiple partners, including freeloaders, increases host fitness in a multispecies mutualism. 
Proceedings of the National Academy of Sciences of the United States of America, 107, 17234-17239.

Pringle, E.G., Dirzo, R. \& Gordon, D.M. (2012) Plant defense, herbivory, and the growth of Cordia alliodora tree and their symbiotic Azteca ant colonies. Oecologia, 170, 677-685.

R Core Development Team (2012) R: A Language and Environment for Statistical Computing. R Core Development Team, Vienna, Austria. http://www. R-project.org/.

Rhoades, D. (1979) Evolution of plant chemical defense against herbivores. Herbivores: Their Interaction with Secondary Plant Metabolites (eds G.A. Rosenthal \& D.H. Janzen), pp. 3-54. Academic Press, New York, NY.

Rudgers, J.A. \& Gardener, M.C. (2004) Extrafloral nectar as a resource mediating multispecies interactions. Ecology, 85, 1495-1502.

Rutter, M.T. \& Rausher, M.D. (2004) Natural selection on extrafloral nectar production in Chamaecrista fasciculata: the costs and benefits of a mutualism trait. Evolution, 58, 2657-2668.

Scogin, R. (1985) Nectar constituents of the Cactaceae. The Southwestern Naturalist, 30, 77-82

Shenoy, M., Radhika, V., Satish, S. \& Borges, R.M. (2012) Composition of extrafloral nectar influences interactions between the myrmecophyte
Humboldtia brunonis and its ant associates. Journal of Chemical Ecology, 38, 88-99.

Trager, M.D. \& Bruna, E.M. (2006) Effects of plant age, experimental nutrient addition and ant occupancy on herbivory in a neotropical myrmecophyte. Journal of Ecology, 94, 1156-1163.

Vasconcelos, H.L. \& Davidson, D.W. (2000) Relationship between plant size and ant associates in two Amazonian ant-plants. Biotropica, 32, 100-111.

Villamil, N., Marquez-Guzman, J. \& Boege, K. (2013) Understanding ontogenetic trajectories of indirect defence: ecological and anatomical constraints in the production of extrafloral nectaries. Annals of Botany, doi: 10.1093/aob/ mct005.

Wäckers, F.L. \& Bonifay, C. (2004) How to be sweet? Extrafloral nectar allocation by Gossypium hirsutum fits optimal defense theory predictions. Ecology, 85, 1512-1518.

Wilder, S.M. \& Eubanks, M.D. (2010) Extrafloral nectar content alters foraging preferences of a predatory ant. Biology Letters, 6, 177-179.

Young, T.P., Stubblefield, C.H. \& Isbell, L.A. (1997) Ants on swollen-thorn acacias: species coexistence in a simple system. Oecologia, 109, 98-107.

Received 14 September 2013; accepted 16 December 2013

Handling Editor: Dan Flynn 